\title{
IDENTIFIKASI FAKTOR-FAKTOR BERPENGARUH TERHADAP KINERJA INSEMINATOR DALAM MENUNJANG KEBERHASILAN INSEMINASI BUATAN PADA PROGRAM UPSUS SIWAB DI BALI
}

\author{
SURANJAYA, I G., N. P. SARINI., DAN M. DEWANTARI \\ Fakultas Peternakan, Universitas Udayana \\ e-mail: suranjaya_gede@unud.ac.id
}

\begin{abstract}
ABSTRAK
Penelitian dilaksanakan dengan metoda survei dengan tujuan untuk mengetahui faktor-faktor yang berpengaruh terhadap kinerja inseminator dan keberhasilan inseminasi buatan (IB) dalam upaya menunjang program Upsus Siwab di Bali. Penetapan responden dilakukan secara purposive sampling terhadap inseminator IB di seluruh Bali. Data diperoleh dari hasil wawancara, catatan dari para inseminator dan informasi dari instansi terkait. Analisis data dilakukan secara deskriptif dan multiple regression dilanjutkan dengan step-wise untuk mengidentifikasi faktor-faktor yang paling berperan. Hasil penelitian menunjukkan kinerja inseminator secara bersama-sama dipengaruhi secara nyata $(\mathrm{P}<0,05)$ oleh faktor umur $\left(\mathrm{X}_{1}\right)$, jenjang pendidikan $\left(\mathrm{X}_{2}\right)$, jumlah keluarga $\left(\mathrm{X}_{3}\right)$, waktu yang tersedia $\left(\mathrm{X}_{4}\right)$, lama pelatihan $\left(\mathrm{X}_{5}\right)$, lama menjadi inseminator $\left(\mathrm{X}_{6}\right)$, jarak lokasi $\left(\mathrm{X}_{7}\right)$ dan status kepegawaian $\left(\mathrm{X}_{8}\right)$. Melalui analisa step-wise, maka diperoleh jumlah ternak yang dapat di IB per periode (Y1) secara nyata dipengaruhi oleh $\mathrm{X}_{4}, \mathrm{X}_{6}$ dan $\mathrm{X}_{7}$ dengan persamaann $\mathrm{Y}_{1}=15,35 \mathrm{X}_{4}+16,65 \mathrm{X}_{6}+28,57 \mathrm{X}_{7}-142,36(\mathrm{P}<0,05)$ dengan $\mathrm{R}^{2}=0,575$. Untuk servis per conception $\left(\mathrm{Y}_{2}\right)$ dan conception rate $\left(\mathrm{Y}_{3}\right)$ secara nyata dipengaruhi oleh $\mathrm{X}_{6}$ dengan persamaan masing-masing $\mathrm{Y}_{2}=1,273+0,088 \mathrm{X}_{6}$ dengan $\mathrm{R}^{2}=0,375$ dan $\mathrm{Y}_{3}=44,49+0,843 \mathrm{X}_{6} \operatorname{dengan} \mathrm{R}^{2}=0,364$, sementara calving rate $\left(\mathrm{Y}_{4}\right)$ dipengaruhi oleh $\mathrm{X}_{6}$ dan $\mathrm{X}_{7}$ dengan persamaan $\mathrm{Y}_{4}=45,28+0,95 \mathrm{X}_{6}-0,368 \mathrm{X}_{7}$ dengan $\mathrm{R}^{2}=0,408$. Dari beberapa faktor yang teridentifikasi, ternyata peubah lama menjadi inseminator atau pengalaman sebagai inseminator $\left(\mathrm{X}_{6}\right)$ adalah paling berperanan terhadap kinerja inseminator untuk menunjang keberhasilan IB pada pelaksanaan program Upsus Siwab di Bali.
\end{abstract}

Kata kunci: inseminator, inseminasi buatan, upsus siwab

\section{IDENTIFICATION OF FACTORS AFFECTING THE INSEMINATOR PERFORMANCE IN SUPPORTING THE SUCCESS OF ARTIFICIAL INSEIMINATION AT THE UPSUS SIWAB PROGRAM IN BALI}

\begin{abstract}
The study was conducted by survey method with the aim to find out the factors that influence the performance of inseminator and the success of artificial insemination (AI) in an effort to support the Upsus Siwab program in Bali. Determination of respondents is done by purposive sampling of IB inseminators throughout Bali. Data obtained from interviews, notes from inseminators and information from relevant agencies. Data analysis was performed descriptively and multiple regression was followed by step-wise to identify the factors that had the most role. The results showed that inseminator performance was significantly affected $(\mathrm{P}<0.05)$ by factors of age $\left(\mathrm{X}_{1}\right)$, education level $\left(\mathrm{X}_{2}\right)$, number of families $\left(\mathrm{X}_{3}\right)$, available time $\left(\mathrm{X}_{4}\right)$, length of training $\left(\mathrm{X}_{5}\right)$, long as an inseminator $\left(\mathrm{X}_{6}\right)$, location distance $\left(\mathrm{X}_{7}\right)$ and staffing status $\left(\mathrm{X}_{8}\right)$. Through step-wise analysis, the number of animals that can be inseminated per period $\left(\mathrm{Y}_{1}\right)$ is significantly affected by $\mathrm{X}_{4}, \mathrm{X}_{6}$ and $\mathrm{X}_{7}$ with the equation $\mathrm{Y}_{1}=15.35 \mathrm{X}_{4}+16.65 \mathrm{X}_{6}+28.57 \mathrm{X}_{7}$ 142.36 $(\mathrm{P}<0.05)$ with $\mathrm{R}^{2}=0.575$. Service per conception $\left(\mathrm{Y}_{2}\right)$ and conception rate $\left(\mathrm{Y}_{3}\right)$ are significantly affected only by $\mathrm{X}_{6}$ with the respective equations $\mathrm{Y}_{2}=1,273+0.088 \mathrm{X}_{6}$ with $\mathrm{R}^{2}=0.375$ and $\mathrm{Y}_{3}=44.49+0.885 \mathrm{X}_{6}$ with $\mathrm{R}^{2}$ $=0.364$, while calving rate $\left(\mathrm{Y}_{4}\right)$ is influenced by $\mathrm{X}_{6}$ and $\mathrm{X}_{7}$ with the equation $\mathrm{Y}_{4}=45.28+0.95 \mathrm{X}_{6}-0.368 \mathrm{X}_{7}$ with $\mathrm{R}^{2}$ $=0.408$. Of the several factors identified, it turns out that the long as an inseminator (X6) is the most important role in inseminator performance to support the success of AI in implementing the Upsus Siwab program in Bali.
\end{abstract}

Keywords: inseminator, artificial insemination, upsus siwab 


\section{PENDAHULUAN}

Program UPSUS SIWAB (Upaya Khusus Sapi Indukan Wajib Bunting) adalah program pemerintah yang dilaksanakan untuk mewujudkan swasembada daging secara nasional, mandiri dalam pemenuhan pangan asal hewan dan utamanya adalah untuk meningkatkan kesejahteraan peternak. Salah satu program utama Upsus Siwab adalah pencapaian peningkatan populasi ternak sapi melalui Inseminasi Buatan (IB). Pada tahun pertama pelaksanaannya yaitu tahun 2017 pencapaian program Upsus Siwab ini masih rendah yaitu hanya tercapai $27,5 \%$ jumlah kelahiran pedet baru dari total target 3 juta ekor.

Inseminasi Buatan (IB) adalah teknologi yang diterapkan pada program Upsus Siwab ini dengan menggunakan sumber semen dari pejantan-pejantan unggul. Kemudahan yang diberikan kepada peternak untuk meningkatkan pelaksanaan IB itu misalnya adalah dengan menggratiskan biaya IB itu. Pada 2017 tahun pertama pelaksanaan Upsus Siwab, sebanyak 4 juta ekor sapi betina disiapkan sebagai penerima atau akseptor IB dan dari jumlah tersebut ditargetkan akan dihasilkan 3 juta ekor. Namun, hingga awal September, berdasarkan data kumulatif secara nasional, sapi yang dapat di-IB baru sebanyak 2.443.658 ekor atau 60,7\% dari target dengan angka kebuntingan mencapai 829.555 ekor atau 27,5\% dari target (Andhika, 2017). Sementara untuk di Bali pada pelaksanaan Upsus Siwab tahun ke-2 dari data kumulatif 1 Januari - 13 Desember 2018 telah ada kelahiran pedet sebanyak 48.222 ekor, namun bila dilihat dari jumlah semen beku yang didistribusilkan yaitu mencapai sejumlah 96.012 dosis dengan realisasi kebuntingan mencapai 58.468 ekor induk bunting maka capaian ini masih belum optimal (Sugiono, 2018). Mengingat belum optimalnya capaian target Upsus Siwab itu, maka perlu diperhatikan faktor - faktor yang menjadi kendala dalam pelaksanaan dari program IB.

Faktor karakteristik inseminator dalam pelaksanaan IB merupakan salah satu dari beberapa faktor penentu keberhasilan IB itu. Keterampilan dan karakter inseminator dalam melaksanakan IB tentunya sangat tergantung dari pengalamannya dalam menginseminasi ternak, pelatihan-pelatihan teknis yang berhubungan dengan inseminasi yang sudah diikuti dan waktu yang disediakan untuk menginseminasi.

Keberhasilan kelahiran pedet (anak sapi) adalah salah satu sumber pendapatan bagi peternak, sementara disisi yang lain biaya mengawinkan ternak dengan IB adalah termasuk sebagai salah satu sumber biaya dalam usaha pemeliharaan ternak sapi. Apabila tidak digratiskan, biaya IB itu adalah dihitung per satu kali ternak di-IB, dan biasanya belum ada jaminan ternak itu akan berhasil bunting. Biasanya, pemungutan biaya IB untuk yang pertama kali lebih tinggi dibandingkan IB untuk yang kedua; dan ketiga lebih murah dari yang kedua, dan seterusnya. Dengan demikian jumlah kelahiran pedet dan jumlah biaya yang dikeluarkan untuk menghasilkan pedet itu adalah sebagai cerminan dari keberhasilan pelaksanaan IB dan hal tersebut tergantung dari faktor-faktor yang berkaitan dengan karakteristik dan ketrampilan yang dimiliki oleh para inseminator.

\section{METODE PENELITIAN}

\section{Metode Penelitian}

Penelitian ini dilaksanakan dengan metoda survei terhadap para petugas inseminator dan para peternak dengan sapi bali betinanya yang ditetapkan sebagai akseptor IB pada tahun ke-2 dari pelaksanaan program UPSUS-SIWAB.

\section{Penetapan responden}

Penetapan responden dilakukan secara "purposive sampling" yaitu teknik pengambilan sampel dengan menyertakan beberapa pertimbangan berkenaan dengan penelitian yang dilakukan. Penentuan responden dilakukan berdasarkan kriteria: 1). Inseminator yang meng-IB sapi induk akseptor, 2). Peternak adalah peserta program Upsus Siwab di Bali, 3) sapi betinanya ditetapkan sebagai akseptor IB. Responden mencakup para inseminator IB dengan wilayah kerja atau melayani IB bagi ternak sapi di seluruh daerah di Bali serta para peternak sapi bali induk untuk menelusuri kinerja inseminator. Ukuran sampel ditetapkan secara proporsional berdasarkan jumlah inseminator yang aktif di masing-masing wilayah/kabupaten.

\section{Pengumpulan Data.}

Teknik pengumpulan data yang digunakan dalam penelitian ini adalah:

Survey lapangan yaitu teknik pengumpulan data dengan menggunakan kuesioner/daftar pertanyaan yang telah dipersiapkan terlebih dahulu

Wawancara/interview yaitu teknik untuk menggali informasi dan data untuk kepentingan penelitian dengan melakukan tanya- jawab atau dialog antara peneliti dan responden.

Data sekunder mengenai populasi sapi induk akseptor IB dan jumlah inseminator yang beroperasi di masing-masing wilayah diperoleh dari Dinas Peternakan dan Puskeswan setempat.

\section{Analisis Data}

Data yang diperoleh pada penelitian ini dianalisis secara deskriptif dan untuk mengidentifikasi faktor- 
faktor profi/karakter inseminator yang berkaitan dengan kinerjanya, maka dilakukan dengan:

Analisis deskriptif untuk melihat karakter faktorfaktor yang berkaitan dengan kinerja dari inseminator.

Regresi linear berganda dilanjutkan dengan step wise, untuk menguji faktor-faktor profil/karakteristik yang berkaitan dengan kinerja inseminator yang paling berperan terhadap indikator keberhasilan IB, dengan persamaan:

$$
\begin{aligned}
& \mathrm{Y}=\alpha+\beta_{1} \mathrm{X}_{1}+\beta_{2} \mathrm{X}_{2}+\ldots \ldots+\beta_{\mathrm{n}} \mathrm{X}_{\mathrm{n}}+\mathrm{D}_{\mathrm{i}} \\
& \begin{array}{ll}
\text { dimana: } & \\
\mathrm{Y} & \text { indikator keberhasilan IB } \\
\alpha & : \text { Intersep } \\
\beta_{1} \beta_{2 \ldots \ldots} \beta_{\mathrm{n}} & : \text { Koefisien regresi ke-1 sampai ke }-\mathrm{n} \\
\mathrm{X}_{1}, \mathrm{X}_{2} \ldots . . \mathrm{X}_{\mathrm{n}}: \text { Faktor/karakteristik inseminator ke-1 sampai } & \quad \text { ke-n } \\
\mathrm{D}_{\mathrm{i}} & : \text { dummy variabel }
\end{array}
\end{aligned}
$$

\section{HASIL DAN PEMBAHASAN}

\section{Karakteristik Inseminator IB.}

Kisaran umur inseminator IB di Bali pada pelaksanaan program Upsus Siwab tahun 2018 adalah berkisar 25 - 65 tahun dengan rataan $45 \pm 11,29$ tahun. Sebanyak 89,47\% sudah berumah tangga dan 10,53\% belum dengan kisaran jumlah anggota keluarga $2-7$ orang. Menurut Saragih (2000) secara umum usia mempunyai pengaruh terhadap produktivitas kerja lebih banyak pada pekerjaan yang mengandalkan kekuatan fisik. Jumlah anggota keluarga secara tidak langsung diduga berkaitan dengan intensitas responden dalam melaksanakan pekerjaaannya.

Jenjang pendidikan formal responden paling rendah adalah setingkat SMA yaitu mencapai $71,05 \%$ dan sekitar 28,95\% berpendidikan setingkat S1. Semakin tinggi tingkat pendidikan, responden akan memiliki kemampuan yang semakin baik pula dalam mengadopsi inovasi khususnya tentang IB. Responden 100\%

Tabel 1. Deskripsi karakteristik inseminator di Bali

\begin{tabular}{lcc}
\hline \multicolumn{1}{c}{ Variabel Karakteristik } & Nilai & Sd \\
\hline $\begin{array}{l}\text { Rataan Umur (th) } \\
\text { Jenjang Pedidikan (\%) } \\
\quad \text { SMA } \\
\text { - S1 }\end{array}$ & 45,00 & 11,29 \\
Kisaran Jumlah Keluarga (orang) & 71,05 & \\
& 28,95 & \\
Status Pegawai (\%) & $2-7$ & \\
$\quad$ PNS & & \\
$\quad$ Non PNS & 44,74 & \\
Rataan Waktu utk IB per hari (jam) & 55,26 & \\
Rataan Lama Pelatihan (hari) & 10,89 & 1,72 \\
Rataan lama waktu sbg Inseminator (th) & 22,92 & 16,53 \\
Rataan Jarak Lokasi (km) & 13,08 & 7,39 \\
& 11,58 & 8,55 \\
\hline
\end{tabular}

sudah mengikuti pelatihan tentang teknik IB, 44,73\% periksa kebuntingan (PKB) dan 15,78\% assisten teknik reproduksi (ATR).

Lama waktu mengikuti pelatihan dari responden rata-rata $22,92 \pm 16,53$ hari. Melalui pelatihan yang diikuti itu maka seluruh inseminator IB di Provinsi Bali (100\%) pada tahun 2018 telah memiliki surat ijin mengesiminasi (SIMI).

Status kepegawaian para inseminator terdiri atas 44,74\% PNS dan 55,26\% non PNS. Inseminator yang berstatus PNS kadang-kadang juga bertugas sebagai penyuluh peternakan di wilayah kerja operasionalnya. Hal ini merupakan salah satu faktor yang menyebabkan keterbatasan waktu yang dimiliki untuk melaksanakan tugasnya sebagai inseminator.

Faktor lain yang juga memiliki peranan adalah jarak (radius) kerja operasionalnya. Kisaran radius kerja operasional para inseminator di Bali adalah $2-45$ $\mathrm{km}$ dengan rataan $11,58 \pm 8,55 \mathrm{~km}$. Ini menunjukkan bahwa radius kerja operasional itu bisa mencapai jarak cukup jauh bagi lokasi atau wilayah yang lebih luas serta tingkat populasi ternak yang lebih tinggi seperti Buleleng dan Karangasem.

Lama waktu sebagai inseminator (pengalaman) dari responden berkisar 2-27 th dengan rataan $13,08 \pm 7,39$ th. Lama menekuni profesi sebagai inseminator pada penelitian ini adalah sangat beragam. Inseminator yang cukup lama menekuni profesinya sudah tentu sarat dan penuh dengan pengalaman sebaliknya yang baru sudah tentu harus lebih banyak menimba pengalaman dan mengasah keterampilan.

\section{Kinerja Inseminator}

Jumlah ternak yang dapat di-IB per tahun, service per conception, conception rate dan calving rate adalah kriteria yang dapat digunakan untuk menilai kinerja seorang inseminator dan keberhasilan IB.

Tabel 2. Deskripsi kinerja inseminator di Bali

\begin{tabular}{lcc}
\hline \multicolumn{1}{c}{ Variabel Kinerja } & Rataan & $\mathrm{Sd}$ \\
\hline Jumlah IB/tahun (ekor) & 540,76 & 383,32 \\
Servis per Conseption (S/C) kali & 1,19 & 0,14 \\
Conseption Rate (\%) & 63,76 & 15,17 \\
Calving Rate (\%) & 55,17 & 15,17
\end{tabular}

Jumlah ternak yang dapat di-IB per tahun berkisar 40-1375 ekor sapi induk dengan rataan 540,72 $\pm 383,32$ ekor. Ini menunjukkan kondisi yang sangat beragam, seperti terjadi di Kabupaten Jembrana jumlah ternak yang dapat di-IB per tahun oleh seorang inseminator hanya mencapai 40 ekor, sementara di Kabupaten Buleleng, Karangasem dan Gianyar bisa mencapai lebih dari 1000 ekor. Faktor ketrampilan dan pengalaman yang dimiliki, mampu memberikan layanan IB yang baik 
adalah faktor yang sangat menentukan jumlah ternak yang dapat di-IB. Sementara jika seorang inseminator hanya dapat meng-IB ternak dengan jumlah yang sedikit di suatu lokasi dengan tingkat populasi sapi induk yang cukup tinggi. Ini menunjukkan bahwa tipe petugas inseminator seperti itu memiliki kinerja yang kurang baik atau tidak dapat memberi layanan yang memuaskan bagi peternak.

Rentang angka service per conception (S/C) sapi akseptor IB pada penelitian ini berkisar 1,01 - 1,60 dengan rataan $1,19 \pm 0,14$. Ini menunjukkan bahwa inseminator IB di Bali secara umum pernah mengIB sapi induk lebih dari 1 kali sampai ternak tersebut mengalami kebuntingan. Menurut Iswoyo dan Priyantini (2008) terdapat beberapa faktor yang menyebabkan tingginya besaran S/C pada seekor sapi induk antara lain, karena: (1) peternak terlambat mendeteksi saat berahi atau terlambat melaporkan berahi sapinya kepada inseminator, (2) adanya kelainan pada alat reproduksi induk sapi, (3) inseminator kurang terampil, (4) fasilitas pelayanan inseminasi yang terbatas, dan (5) kurang lancarnya transportasi. Seandainya biaya IB pada program Upsus Siwab ini tidak digratiskan dan nilai S/C nya lebih besar dari 1 yaitu sapi induk tidak bunting karena kelainan, kegagalan IB ataupun akibat kesalahan inseminator, maka secara langsung akan memperbesar biaya untuk menghasilkan seekor pedet. Dengan demikian, besar kecilnya pengeluaran biaya untuk menghasilkan pedet juga tergantung dengan keterampilan inseminator.

Tingkat conception rate (CR) atau jumlah ternak yang berhasil bunting antar inseminator pada penelitian ini sangat bervariasi yaitu berkisar dari 39,50-95\%, dengan rataan $63,76 \pm 15,17 \%$. Nilai CR terendah terdapat di Kabupaten Jembrana sedangkan tertinggi terdapat di Kabupaten Klungkung. Hasil penelitian Rivera et al. (2005) pada sapi perah mendapatkan variasi nilai CR lebih banyak disebabkan oleh ragam kualitas kinerja dari para inseminator. Rataan persentase kebuntingan (CR) sapi induk dari hasil IB semua inseminator pada penelitian ini adalah lebih besar 50\%. Ini menunjukkan bahwa kinerja para inseminator IB dikatagorikan cukup baik. Menurut Oltenacu et al. (1981) terdapat 3 katagori inseminator yaitu: 1). inseminator belum berpengalaman jika memiliki nilai $\mathrm{CR}<0,42$; 2). Inseminator berkemampuan "rata-rata" atau "sedang" jika nilai $\mathrm{CR}=0,50 ; 3$ ). inseminator professional dengan nilai $\mathrm{CR}>0,58$. Herawati (2012) menyatakan bahwa seorang inseminator dapat dinyatakan memiliki kinerja yang baik apabila memiliki nilai CR berkisar $59,26-77,27 \%$.

Angka calving rate (CvR) dari sapi induk akseptor IB di Bali pada penelitian ini sangat beragam berkisar 33,50 - 81,68\% dengan rata-rata 55,19 $\pm 13,61 \%$.
Angka CvR tertinggi pada sapi akseptor dicapai oleh inseminator IB di Kabupaten Karangasem sedangkan yang terendah dicapai oleh inseminator di Kabupaten Buleleng. Ketrampilan inseminator dalam melaksanakan inseminasi merupakan salah satu faktor keberhasilan IB. Waktu optimum untuk melakukan inseminasi juga harus diperhitungkan dengan waktu kapasitasi, yaitu suatu proses fisiologis yang dialami oleh spermatozoa di dalam saluran kelamin betina untuk memperoleh kapasitas atau kesanggupan membuahi ovum. Disamping itu menurut Murtidjo (1993) bahwa pengetahuan tentang deteksi estrus sapi betina harus dikuasai pula oleh seorang inseminator sehingga pelaksanaan IB sanggup menghasilkan tingkat kebuntingan yang tinggi. Sementara menurut Tappa (2012) waktu yang tepat untuk melakukan inseminasi adalah pada saat turunnya sel telur dan dimasukkannya semen ke dalam uterus dan apabila itu berjalan normal dan baik maka hanya sekitar 4 persen dari jumlah ternak yang di-IB akan minta kawin lagi.

\section{Peranan Faktor Karakteristik Inseminator terhadap Kinerja}

Dengan menggunakan analisis regresi berganda diperoleh bahwa kinerja inseminator dipengaruhi oleh faktor karakteristik inseminator seperti: umur $\left(\mathrm{X}_{1}\right)$, jenjang pendidikan $\left(\mathrm{X}_{2}\right)$, jumlah keluarga $\left(\mathrm{X}_{3}\right)$, waktu yang tersedia $\left(\mathrm{X}_{4}\right)$, lama pelatihan $\left(\mathrm{X}_{5}\right)$, lama menjadi inseminator $\left(\mathrm{X}_{6}\right)$, jarak lokasi $\left(\mathrm{X}_{7}\right)$ dan status kepegawaian/dummy $\left(\mathrm{X}_{8}\right)$. Hasil analisis regresi berganda dari peubah dependent dan independent pada penelitian ini ditampilkan pada Tabel 3 .

Tabel 3. Nilai koefisien regresi antara kinerja dan faktor karakteristik inseminator

\begin{tabular}{|c|c|c|c|c|c|c|c|c|}
\hline \multirow{2}{*}{$\begin{array}{l}\text { Koefisien } \\
\text { Regresi }\end{array}$} & \multicolumn{2}{|c|}{ Jumlah IB/th $\left(Y_{1}\right)$} & \multicolumn{2}{|c|}{$S / C\left(Y_{2}\right)$} & \multicolumn{2}{|c|}{$\mathrm{CR}\left(\mathrm{Y}_{3}\right)$} & \multicolumn{2}{|c|}{$\operatorname{CvR}\left(\mathrm{Y}_{4}\right)$} \\
\hline & Nilai & Sig & Nilai & Sig & Nilai & Sig & Nilai & Sig \\
\hline $\begin{array}{c}\text { Konstanta } \\
\left(\mathrm{b}_{0}\right)\end{array}$ & 767,18 & $0,19^{\text {ns }}$ & 1,330 & & 29,976 & $0,155^{\text {ns }}$ & 41,287 & $0,06^{*}$ \\
\hline$b_{1}$ & $-9,99$ & $0,11^{\mathrm{ns}}$ & 0,001 & $0,85^{\mathrm{ns}}$ & $-0,034$ & $0,88^{\mathrm{ns}}$ & $-0,111$ & $0,64^{\mathrm{ns}}$ \\
\hline$b_{2}$ & $-213,44$ & $0,08^{\mathrm{ns}}$ & $-0,019$ & $0,74^{\mathrm{ns}}$ & 5,778 & $0,189^{\text {ns }}$ & 0,835 & $0,85^{\text {ns }}$ \\
\hline$b_{3}$ & $-19,06$ & $0,64^{\mathrm{ns}}$ & 0,005 & $0,80^{\text {ns }}$ & 0,449 & $0,76^{\mathrm{ns}}$ & 0,737 & $0,63^{\mathrm{ns}}$ \\
\hline $\mathrm{b}_{4}$ & 8,18 & $0,73^{\mathrm{ns}}$ & $-0,002$ & $0,84^{\mathrm{ns}}$ & 0,510 & $0,55^{\mathrm{ns}}$ & 0,735 & $0,41^{\mathrm{ns}}$ \\
\hline$b_{5}$ & 6,08 & $0,03^{*}$ & 0,001 & $0,41^{\mathrm{ns}}$ & $-0,157$ & $0,111^{\mathrm{ns}}$ & $-0,011$ & $0,29^{n s}$ \\
\hline$b_{6}$ & 22,71 & $0,04^{*}$ & 0,010 & $0,04^{*}$ & 1,082 & $0,007^{*}$ & 1,038 & $0,012^{*}$ \\
\hline$b_{7}$ & 27,29 & $0,00^{* *}$ & $-0,003$ & $0,26^{\mathrm{ns}}$ & $-0,166$ & $0,360^{\text {ns }}$ & $-0,422$ & $0,032^{*}$ \\
\hline $\mathrm{b}_{8}$ & 113,91 & $0,16^{\mathrm{ns}}$ & 0,002 & $0,95^{\mathrm{ns}}$ & $-1,160$ & $0,682^{n s}$ & $-0,737$ & $0,81^{\mathrm{ns}}$ \\
\hline $\begin{array}{l}\text { Koef. De- } \\
\text { terminasi } \\
\left(\mathrm{R}^{2}\right)\end{array}$ & 0,64 & & 0,35 & & 0,327 & & 0,339 & \\
\hline F Hitung & 9,17 & $0,00^{* *}$ & 4,18 & $0,039^{*}$ & 3,246 & $0,009^{* *}$ & 3,374 & $0,007^{* *}$ \\
\hline
\end{tabular}

Dari Tabel 3 nampak bahwa peubah dependen yaitu $\mathrm{Y}_{1}, \mathrm{Y}_{2} ; \mathrm{Y}_{3}$ dan $\mathrm{Y}_{4}$ dipengaruhi bersama-sama secara nyata oleh peubah independen $\mathrm{X}_{1 ;} \mathrm{X}_{2} ; \mathrm{X}_{3} ; \mathrm{X}_{4} ; \mathrm{X}_{5} ; \mathrm{X}_{6} ; \mathrm{X}_{7}$ dan Dummy $\left(\mathrm{X}_{8}\right)$ dengan nilai koefisien determinasi 
masing-masing $\mathrm{R}_{1}^{2}=0,64 ; \mathrm{R}_{2}^{2}=0,35 ; \mathrm{R}_{3}^{2}=0,327$ dan $\mathrm{R}_{4}^{2}=0,339$ serta dengan nilai $\mathrm{F}_{\text {hitung }}$ dari ketiga persamaan regresi itu masing-masing: $\mathrm{F}_{\text {hit }} 1=9,17$ $(\mathrm{P}<0,01) ; \mathrm{F}_{\text {hit }}{ }^{2}=4,18(\mathrm{P}<0,05) ; \mathrm{F}_{\mathrm{hit}} 3=3,246(\mathrm{P}<0,01)$ dan $\mathrm{F}_{\text {hit }} 4=3,374(\mathrm{P}<0,01)$.

Hasil analisis menunjukkan bahwa faktor lama pelatihan $\left(\mathrm{X}_{5}\right)$, lama pengalaman menjadi inseminator $\left(\mathrm{X}_{6}\right)$ dan jarak wilayah kerja $\left(\mathrm{X}_{7}\right)$ dari para inseminator itu memberi kontribusi yang nyata $(\mathrm{P}<0,05)$ terhadap jumlah ternakyang dapat di-IB pertahun $\left(\mathrm{Y}_{\mathrm{i}}\right)$. Sementara untuk $\mathrm{Y}_{2}$ dan $\mathrm{Y}_{3}$ hanya dipengaruhi atau berkaitan secara nyata $(\mathrm{P}<0,05)$ dengan lama pengalaman menjadi inseminator $\left(\mathrm{X}_{6}\right)$, sedangkan untuk $\mathrm{Y}_{4}$ (calving rate/ CvR) berkaitan atau dipengaruhi secara bersama-sama oleh $\mathrm{X}_{6}$ dan $\mathrm{X}_{7}$ dengan tingkat signifikansi $\mathrm{P}<0,05$ ). Peubah lama pengalaman menjadi inseminator $\left(\mathrm{X}_{6}\right)$ mempunyai nilai signifikansi yang nyata $(\mathrm{P}<0,05)$ pada ke-4 model persamaan tersebut. Terdapatnya perbedaan kinerja antar inseminator sesuai dengan hasil penelitian Anggraeni et al. (2012) mendapatkan bahwa terjadi perbedaan kecil angka non return rate saat dosis sperma sekitar 10 juta - 20 juta apabila dipakai oleh inseminator dengan ketrampilan baik, tetapi terjadi perbedaan sekitar 10\% ketika IB dilakukan oleh inseminator kurang trampil. Faktor keterampilan dan keahlian seorang inseminator sebenarnya adalah bersumber dari lama waktu pengalamannya serta dari pelatihan-pelatihan teknis yang diikuti. Faktor jarak wilayah kerja juga berpengaruh nyata positif terhadap jumlah ternak yang dapat di-IB/tahun karena semakin luas wilayah maka pelanggan ataupun akseptor IB juga bertambah sehingga jumlah ternak yang di-IB/tahun juga bertambah. Namun sebaliknya jarak wilayah operasional inseminator itu berpengaruh nyata negatif terhadap CvR. Di wilayah yang luas sarana maupun prasarana transportasi dan komunikasi cukup sulit dan belum memadai, sehingga peternak sulit berkomunikasi dengan inseminator sehingga sangat menyulitkan inseminator untuk melakukan IB tepat waktu dan memberikan layanan optimal. Selain itu juga sering mengalami kesulitan dalam memperoleh pasokan nitrogen cair, hal itu menyebabkan tangki penyimpan semen dalam kondisi kekurangan nitrogen sehingga kualitas semen menurun dan tidak layak digunakan untuk layanan IB.

Selanjutnya dengan melakukan stepwise yaitu dengan mengeliminasi peubah-peubah independen $\left(\mathrm{X}_{\mathrm{i}}\right)$ yang tidak nyata berkaitan atau berpengaruh dengan peubah dependen $\left(\mathrm{Y}_{\mathrm{i}}\right)$, maka diperoleh persamaan regresi $\mathrm{Y}_{1}=15,35 \mathrm{X}_{4}+16,65 \mathrm{X}_{6}+28,57 \mathrm{X}_{7}-142,36$ $(\mathrm{P}<0,05)$ dengan $\mathrm{R}^{2} \stackrel{4}{=} 0,575 . \mathrm{Y}_{2}=1,273+0,088 \mathrm{X}_{6}$ dengan $\mathrm{R}^{2}=0,375$ dan $\mathrm{Y}_{3}=44,49+0,843 \mathrm{X}_{6}$ dengan $\mathrm{R}^{2}=0,364$, sementara calving rate $\left(\mathrm{Y}_{4}\right)$ dipengaruhi oleh $\mathrm{X}_{6}$ dan $\mathrm{X}_{7}$ dengan persamaan $\mathrm{Y}_{4}=45,28+0,95 \mathrm{X}_{6}$
- o,368X dengan $\mathrm{R}^{2}=0,408$. Persamaan-persamaan ini memiliki masing-masing koefisien determinasi $\left(\mathrm{R}^{2}\right)$ yang menunjukkan berapa besar peranan perubahan pada peubah dependen yang diakibatkan atau disebabkan oleh perubahan pada peubah independen. Seperti pada persamaan regresi $\mathrm{Y}_{1}$ dengan nilai koefisien determinasi $\mathrm{R}^{2}=0,575$ artinya bahwa sebesar $57,5 \%$ dari jumlah ternak yang dapat di-IB per tahun oleh seorang inseminator berkaitan atau ditentukan secara bersama-sama oleh faktor lama pengalaman dan jarak wilayah kerja inseminator, sementara 42,5\% lagi ditentukan oleh faktor yang lain.

\section{SIMPULAN}

Faktor karakteristik inseminator dapat diidentifikasi memiliki kontribusi terhadap kinerja inseminator dalam menunjang keberhasilan IB seperti: umur, jenjang pendidikan, jumlah keluarga, waktu yang dimiliki, lama pelatihan teknis, lama waktu sebagai inseminator, jarak wilayah kerja dan status kepegawaian. Lama pelatihan teknis, lama waktu sebagai inseminator dan jarak wilayah kerja adalah memiliki peranan nyata namun faktor lama waktu sebagai inseminator paling berperanan terhadap kinerja inseminator dalam upaya menunjang keberhasilan IB pada program Upsus Siwab di Bali.

\section{UCAPAN TERIMA KASIH}

Penulis mengucapkan terima kasih kepada Rektor Universitas Udayana, Dekan Fakultas Peternakan serta Ketua LPPM Universitas Udayana atas bantuan dana serta fasilitas yang diberikan sehingga penelitian dapat terlaksana dengan baik. Ucapan terima kasih juga disampaikan kepada para inseminator IB, para peternak responden dan tim peneliti atas bantuan dan kerjasamanya selama pelaksanaan penelitian.

\section{DAFTAR PUSTAKA}

Andhika, P. 2017. Capaian Upsus Siwab masih rendah. http://mediaindonesia.com/read/detail/122891capaian-upsus-siwab-masih-rendah. E-paper Media Indonesia. Diakses Januari 2019.

Anggraeni, A., L. Praharani, T. Herawati, P. Situmorang, L. Widyawati, D. Utami, A. Argiris, dan R. Harsono. 2012. Kajian Efektivitas Inseminasi Buatan Menggunakan Semen Beku Pada Dosis Berbeda. Laporan Pengembangan Inseminasi Buatan. Penelitian Kerjasama Balitnak-BIB Lembang dan KPSBU Lembang. $27 \mathrm{hlm}$.

Iswoyo dan W. Priyantini. 2008. Performans Reproduksi Sapi Peranakan Simmental (Psm) Hasil Inseminasi 
buatan di kabupaten Sukoharjo Jawa Tengah. J. Ilmiah Ilmu-Ilmu Peternakan. 3(4): 125-133.

Murtidjo, B.A., 1993. Beternak Sapi Potong. Kanisius. Yogyakarta.

Oltenacu, P. A, T. R. Rounsaville, R. A. Milligan, and R. H. Foote. 1981. Systems analysis for designing reproductive management programs to increase production and profit in dairy herds. Journal of Dairy Science. 64(10): 2096-2104.

Rivera, H., H. Lopez and P. M. Fricke. 2005. Use of intravaginal progesterone-releasing inserts in a synchronization protocol before timed ai and for synchronizing return to estrus in holstein heifers. Department of Dairy Science, University of Wisconsin, Madison 53706. Journal of Dairy Science. 88(3): 957-968.

Saragih, B, 2000. Agribisnis Berbasis Peternakan. USESE Foundation dan Pusat Studi Pembangunan IPB.
Sugiono, 2018. Akhir tahun Bali panen pedet 48.222 ekor. https://regional.kontan.co.id/news/akhirtahun-bali-panen-pedet-upsus-siwab-48222-ekor. Kontan. Co.id. News data financial tools. Jakarta. Diakses Desember 2018.

Herawati, T.., A. Anggraeni., L. Praharani., D. Utami dan A. Argiris. 2012. Peran Inseminator dalam Keberhasilan Inseminasi Buatan pada Sapi Perah. Informatika Pertanian, Vol. 21 No.2, 81-88. T.

Tappa, B., R. Harahap, S. Said, R. Ridwan, H. Yanwa, dan E. Sophion. 2012. Upaya Perbaikan Mutu Genetik Sapi Potong Dan Usaha Tani Hijauan Makanan Ternak Dl Kabupaten Belu, NTT. Pengembangan wilayah perbatasan NTT melalui penerapan teknologi. http: //www. elib.pdii.lipi.go.id/katalog/ index.php/ searchkatalog/ .../9477.[Diunduh tanggal 20 Juli 2019]. 